\title{
Synthesis of N-(3-chloro-4-fluorophenyl)-6-nitro-7-((tetrahydrofuran-3-yl) oxy) quinazolin-4-amine
}

\author{
Caolin Wang ${ }^{1}$, Yiqiang Ouyang and Zhou Lan ${ }^{1, \text { a }}$
}

${ }^{1}$ School of Pharmacy, Jiangxi Science \& Technology Normal University, Nanchang 330013, China

*alan8709@yeah.net

\section{Keywords: Afatinib; Synthesis; Optimized}

\begin{abstract}
Afatinib (1) exhibited potential biological activities in medicine. There are shortcomings in the synthesis route of afatinib in the literature, the product yield is low and the post-processing is complicated. Therefore, in this paper, the two-step synthetic route of afatinib was optimized. The two-step reaction is discussed the reaction reagent and the feed ratio on the reaction yield were investigated. The optimized reaction conditions are as follows: $n$ (compounds 4): $n$ (4-chloro-7-fluoro-6-nitro-quinazolineand) = 1:1.2; n (compounds 5): n ((S)-tetrahydrofuran-3-ol): $\mathrm{n}(60$ percent $\mathrm{NaH})=1: 2.3: 3$. The improved process has the advantages of mild reaction conditions, simple operation and low cost. The structures were confirmed by ${ }^{1} \mathrm{H}$ NMR.
\end{abstract}

\section{Introduction}

Lung cancer treatment has evolved significantly during the past decade but this disease remains the leading cause of cancer-associated mortality worldwide[1]. Non-small cell lung cancer (NSCLC) accounts for almost $85 \%$ of all lung cancer cases and can be divided in squamous cell lung cancer and non-squamous cell lung cancer (mainly adenocarci-noma and large cell carcinoma)[2-3]. It is now well established that NSCLC can be further more classified to different subtypes according to the oncogenic events that drive carcinogenesis at a molecular level[4-5]. The two oncogenic events that currently have an impact in clinical practice are activating mutations of the epidermal growth factor receptor (EGFR) and anaplastic lymphoma kinase (ALK) gene rearrangement[6-7].

In recent years, many quinazoline derivatives were reported as EGFR signal transduction pathway inhibitors, afatinib (Fig. 1) which is a powerful, irreversible tyrosine kinase inhibition of EGFR, with IC50 value (half-maximal inhibitory concentration) of $0.5 \mathrm{nM}$, exhibits potent anti-tumor activity against non small-cell lung cancer(NSCLC), and was approved by the FDA for the treatment of patients with metastatic NSCLC in 2013[8]. In the literature, there are shortcomings in the synthesis route of afatinib (Fig. 2)[9-10], such as, the product yield is low and the post-processing is complicated. Therefore, in this paper, discussed of reaction step (d) and (e) that synthetic methods and routes, the two-step reaction is discussed the reaction reagent and the feed ratio on the reaction yield were investigated.

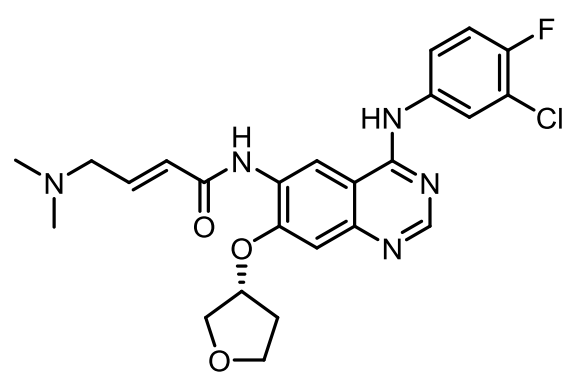

Figure 1. Structures of afatinib 


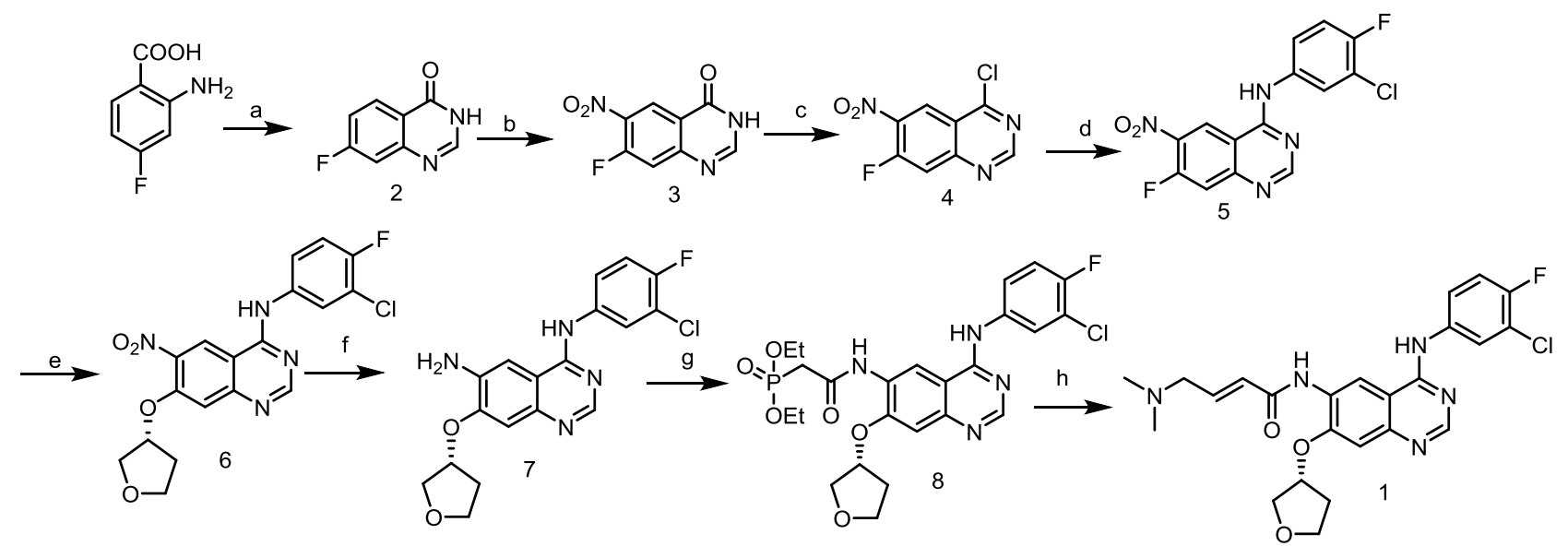

Figure 2. Synthesis of afatinib

\section{Materials and Methods}

NMR spectra were performed using Bruker $400 \mathrm{MHz}$ spectrometers (Bruker Bioscience, Billerica, MA, USA) with TMS as an internal standard. Mass spectra (MS) were taken in ESI mode on Agilent 1100 LC-MS (Agilent, Palo Alto, CA, USA). Elemental analysis was determined on a Carlo-Erba 1106 Elemental analysis instrument (Carlo Erba, Milan, Italy). All the materials were obtained from commercial suppliers and used without purification, unless otherwise specified. Yields were not optimized. TLC analysis was carried out on silica gel plates GF254 (Qindao Haiyang Chemical, China).

\section{Synthesis of Compounds}

The structures and the synthetic route were shown in Scheme 1.<smiles>CC(C)c1cc(N)ccc1F</smiles>

Scheme 1. The synthetic route of compounds 5 and 6

Reagents and Conditions: (d) Acetonitrile, Isopropanol, r. t, 1.5 h; (e) Tetrahydrofuran, 60 percent $\mathrm{NaH}, \mathrm{r} . \mathrm{t}, 1 \mathrm{~h}$.

$\boldsymbol{N}$-(3-chloro-4-fluorophenyl)-7-fluoro-6-nitroquinazolin-4-amine (5). A solution of 4-chloro-7-fluoro-6-nitro-quinazolineand $\quad\left(\begin{array}{lllll}10.0 & \mathrm{~g}, & 0.0440 & \mathrm{~mol}) & \text { and }\end{array}\right.$ 4-chloro-3-trifluoromethyl-phenylamine(7.7 g, $0.0528 \mathrm{~mol})$ in isopropanol $(100 \mathrm{~mL})$, then triethylamine $(5.3 \mathrm{~g}, 0.0528 \mathrm{~mol})$ was added drop-wise at room temperature. The reaction mixture then was stirred at room temperature for $1.5 \mathrm{~h}$, after completion of the reaction (monitored by TLC). The reaction mixture was poured onto water $(500 \mathrm{~mL})$, the mixture was then filtered, the filter cake was washed with water, residue was dried to obtain a powdery solid. We can get $14.1 \mathrm{~g}$ $\mathrm{N}$-(3-chloro-4-fluorophenyl)-7-fluoro-6-nitroquinazolin-4-amine (5). yield: $95.2 \%$. M.p. $261.4{ }^{\circ} \mathrm{C}$ $-262.5{ }^{\circ} \mathrm{C}$. ${ }^{1} \mathrm{H}$ NMR $(400 \mathrm{MHz}, \mathrm{DMSO}) \delta 10.43(\mathrm{~s}, 1 \mathrm{H}), 9.51(\mathrm{~d}, J=7.8 \mathrm{~Hz}, 1 \mathrm{H}), 8.68(\mathrm{~s}, 1 \mathrm{H}), 8.08$ $(\mathrm{d}, J=6.4 \mathrm{~Hz}, 1 \mathrm{H}), 7.79(\mathrm{~d}, J=5.2 \mathrm{~Hz}, 1 \mathrm{H}), 7.76(\mathrm{~s}, 1 \mathrm{H}), 7.45(\mathrm{t}, J=9.0 \mathrm{~Hz}, 1 \mathrm{H})$.

$\mathrm{N}$-(3-chloro-4-fluorophenyl)-6-nitro-7-((tetrahydrofuran-3-yl)oxy)quinazolin-4-amine (6). To the mixture of potassium 60 percent $\mathrm{NaH}(5.0 \mathrm{~g}, 0.1257 \mathrm{~mol})$, anhydrous THF $(300 \mathrm{~mL})$, $(S)$-tetrahydrofuran-3-ol $(8.5 \mathrm{~g}, 0.0964 \mathrm{~mol})$ was added drop-wise at room temperature. The mixture was stirred at room temperature for $1 \mathrm{~h}$. a solution of 
$N$-(3-chloro-4-fluorophenyl)-7-fluoro-6-nitroquinazolin-4-amine (14.1 g, 0.0419 mol) in anhydrous THF (200 mL) was added via a dropping funnel over 1h (the dropping funnel was rinsed with 15 $\mathrm{mL}$ of $\mathrm{THF}$ ) at room temperature and the reaction mixture was stirred at room temperature for $0.5 \mathrm{~h}$, the reaction was monitored by TLC. The solution was concentrated under a reduced pressure and the residue was poured into water with stirring yielding a precipitate, then the mixture was filtered and washed with ice-water and ethanol, dried to afford (S)- $N$-(3-chloro-4-fluorophenyl)-6-nitro-7-((tetrahydrofuran-3-yl)oxy)quinazolin-4-amine (6) as yellow solid (16.7 g, 98.5\%). m.p. $210.1-211.0^{\circ} \mathrm{C} .{ }^{1} \mathrm{H}$ NMR $(400 \mathrm{MHz}, \mathrm{DMSO}) \delta 10.10(\mathrm{~d}, J=11.8$ $\mathrm{Hz}, 1 \mathrm{H}), 9.16(\mathrm{~d}, J=13.2 \mathrm{~Hz}, 1 \mathrm{H}), 8.62(\mathrm{~d}, J=13.4 \mathrm{~Hz}, 1 \mathrm{H}), 8.13(\mathrm{~d}, J=6.8 \mathrm{~Hz}, 1 \mathrm{H}), 7.75(\mathrm{~s}, 1 \mathrm{H})$, $7.45-7.35(\mathrm{~m}, 2 \mathrm{H}), 5.40(\mathrm{~s}, 1 \mathrm{H}), 3.99-3.79(\mathrm{~m}, 4 \mathrm{H}), 2.34(\mathrm{dd}, J=13.8,6.2 \mathrm{~Hz}, 1 \mathrm{H}), 2.04(\mathrm{~d}, J=$ $5.6 \mathrm{~Hz}, 1 \mathrm{H})$.

\section{Results and Discussion}

Effect of Feed Ratio on Yield in Synthetic Route of Compounds 5. The ratio of 4-chloro-7-fluoro-6-nitro-quinazolineand to compounds 4 was varied, and the data shown in Table 1 were obtained. From Table 1, it can be seen that with the increase of the amount of 4-chloro-7-fluoro-6-nitro-quinazolineand, the yield increases, when the ratio of $\mathrm{n}$ (compounds 4): $\mathrm{n}$ (4-chloro-7-fluoro-6-nitro-quinazolineand) $=1: 1.2$ was maximized and increased again 4-chloro-7-fluoro-6-nitro-quinazolineand, cannot improve the product yield, so choice the ratio of $n$ (compounds 4): $\mathrm{n}$ (4-chloro-7-fluoro-6-nitro-quinazolineand) $=1: 1.2$.

Table 1 Effect of feed ratio on yield

\begin{tabular}{ccccc}
\hline & \multicolumn{4}{c}{$\mathrm{n}($ compounds 4): $\mathrm{n}($ 4-chloro-7-fluoro-6-nitro-quinazolineand) } \\
\cline { 2 - 4 } Yield/\% & $1: 1.1$ & $1: 1.2$ & $1: 1.3$ & $1: 1.4$ \\
& $83.1 \%$ & $95.2 \%$ & $95.3 \%$ & $95.5 \%$ \\
\hline
\end{tabular}

Effect of Reagent on Yield in Synthetic Route of Compounds 5. Synthesis of $\mathrm{N}$-(3-chloro-4-fluorophenyl)-6-nitro-7-((tetrahydrofuran-3-yl)oxy)quinazolin-4-amine, the reagents used potassium tert-butoxide in the literature, but the reaction have some shortcomings, such as reaction time is long, the post-processing is complex and the yield is not high. Therefore, the authors intend to use 60 percent $\mathrm{NaH}$ instead of potassium tert-butoxide as the reagent. The data is shown in Table 2.

Table 2 Effect of reagent

\begin{tabular}{ccc}
\hline reagent & reaction time & yield \\
\hline potassium tert-butoxide & $5 \mathrm{~h}$ & $82.1 \%$ \\
60 percent $\mathrm{NaH}$ & $2.5 \mathrm{~h}$ & $98.5 \%$ \\
\hline
\end{tabular}

Effect of Feed Ratio on Yield in Synthetic Route of Compounds 6. The ratio of $(S)$-tetrahydrofuran-3-ol and 60 percent $\mathrm{NaH}$ to compounds 5 was varied, and the data shown in Table 3 were obtained. From Table 3, it can be seen that with the increase of the amount of $(S)$-tetrahydrofuran-3-ol and 60 percent $\mathrm{NaH}$, the yield increases, when the ratio of $\mathrm{n}$ (compounds 4): n $((S)$-tetrahydrofuran-3-ol): $\mathrm{n}(60$ percent $\mathrm{NaH})=1: 2.3: 3$ was maximized and increased again $(S)$-tetrahydrofuran-3-ol and 60 percent $\mathrm{NaH}$, cannot improve the product yield, so choice the ratio of $\mathrm{n}$ (compounds 5): $\mathrm{n}((S)$-tetrahydrofuran-3-ol): $\mathrm{n}(60$ percent $\mathrm{NaH})=1: 2.3: 3$.

Table 3 Effect of feed ratio on yield

\begin{tabular}{ccccccc}
\hline & \multicolumn{5}{c}{$\mathrm{n}($ compounds 5): $\mathrm{n}((S)$-tetrahydrofuran-3-ol): $\mathrm{n}(60$ percent $\mathrm{NaH})$} \\
\cline { 2 - 7 } Yield/\% & $1: 2: 2.5$ & $1: 2: 3$ & $1: 2.3: 3$ & $1: 2.3: 3.5$ & $1: 2.6: 3$ & $1: 2.6: 3.5$ \\
& $78.1 \%$ & $87.8 \%$ & $98.5 \%$ & $91.5 \%$ & $93.5 \%$ & $95.5 \%$ \\
\hline
\end{tabular}




\section{Conclusions}

In conclusion, discussed of reaction step d and reaction step e that synthetic methods and routes, the two-step reaction is discussed the reaction reagent and the feed ratio on the reaction yield were

The synthetic method

$\mathrm{N}$-(3-chloro-4-fluorophenyl)-6-nitro-7-((tetrahydrofuran-3-yl)oxy)quinazolin-4-amine and the reactions conditions were optimized. after optimized, the yield of target compound was higher. Its structure was confirmed by $1 \mathrm{H}$ NMR.

\section{Acknowledgments}

We gratefully acknowledge the generous support provided by Project supported by the Natural Science Foundation of Jiangxi Province (No. 20161BAB215216), Doctoral Scientific Research Foundation of Jiangxi Science \& Technology Normal University and Program of Key Laboratory of Drug Design and Optimization, Jiangxi Science \& Technology Normal University (300098010306) and College Students' Science and Technology Innovation Project of Jiangxi Province.

\section{References}

[1] Worley S. Lung Cancer Research Is Taking On New Challenges: Knowledge of Tumors' Molecular Diversity Is Opening New Pathways to Treatment. P\&T, 2014, 39(10):698-714.

[2] Yang J, Lin J, Liu T, et al. Analysis of lncRNA expression profiles in non-small cell lung cancers (NSCLC) and their clinical subtypes. Lung Cancer, 2014, 85(2):110-115.

[3] Socinski M A, Obasaju C, Gandara D, et al. Clinicopathologic features of advanced squamous non-small cell lung cancer. Journal of Thoracic Oncology Official Publication of the International Association for the Study of Lung Cancer, 2016, 11(9):1411-1422.

[4] Michel DuPage, Alison L. Dooley, Tyler Jacks. Conditional mouse lung cancer models using adenoviral or lentiviral delivery of Cre recombinase. Nature Protocol, 2009, 4(7):1064-1072.

[5] Ercan D, Xu C, Yanagita M, et al. Reactivation of ERK Signaling Causes Resistance to EGFR Kinase Inhibitors. Cancer Discovery, 2012, 2(10):934-947.

[6] Ciardiello F, Tortora G. Epidermal growth factor receptor (EGFR) as a target in cancer therapy: understanding the role of receptor expression and other molecular determinants that could influence the response to anti-EGFR drugs. European Journal of Cancer, 2003, 39(10):1348-1354.

[7] Pulford K, Lamant L, Morris S W, et al. Detection of anaplastic lymphoma kinase (ALK) and nucleolar protein nucleophosmin (NPM)-ALK proteins in normal and neoplastic cells with the monoclonal antibody ALK1. Blood, 1997, 89(4):1394-1404.

[8] Cho B C, Kim H J, Sun M L. Abstract 5408: Enhancement of the anti-tumor activity of afatinib by inhibition of glycolysis in non-small cell lung cancer harboring the EGFR T790M mutation. Cancer Research, 2013, 73(8 Supplement):5408-5408.

[9] Xu X. Afatinib and preparation method of intermediate thereof, WO/2014/183560. 2014.

[10] Gustavsson B, Carlsson B. Tetrahydrofolates in combination with EGFR-inhibitors in the use of treating cancer: EP, EP2617421. 2013. 